Review Article

\title{
Insulin-Like Growth Factor and Epidermal Growth Factor Signaling in Breast Cancer Cell Growth: Focus on Endocrine Resistant Disease
}

\author{
Kallirroi Voudouri, ${ }^{1}$ Aikaterini Berdiaki, ${ }^{1}$ Maria Tzardi, ${ }^{2}$ \\ George N. Tzanakakis, ${ }^{1}$ and Dragana Nikitovic ${ }^{1}$ \\ ${ }^{1}$ Laboratory of Anatomy-Histology-Embryology, School of Medicine, University of Crete, 71003 Heraklion, Greece \\ ${ }^{2}$ Laboratory of Pathology, School of Medicine, University of Crete, 71003 Heraklion, Greece \\ Correspondence should be addressed to Dragana Nikitovic; dnikitovic@med.uoc.gr
}

Received 30 April 2015; Accepted 5 July 2015

Academic Editor: Matthias Stope

Copyright @ 2015 Kallirroi Voudouri et al. This is an open access article distributed under the Creative Commons Attribution License, which permits unrestricted use, distribution, and reproduction in any medium, provided the original work is properly cited.

\begin{abstract}
Breast cancer is the most common type of cancer for women worldwide with a lifetime risk amounting to a staggering total of $10 \%$. It is well established that the endogenous synthesis of insulin-like growth factor (IGF) and epidermal growth factor (EGF) polypeptide growth factors are closely correlated to malignant transformation and all the steps of the breast cancer metastatic cascade. Numerous studies have demonstrated that both estrogens and growth factors stimulate the proliferation of steroid-dependent tumor cells, and that the interaction between these signaling pathways occurs at several levels. Importantly, the majority of breast cancer cases are estrogen receptor- (ER-) positive which have a more favorable prognosis and pattern of recurrence with endocrine therapy being the backbone of treatment. Unfortunately, the majority of patients progress to endocrine therapy resistant disease (acquired resistance) whereas a proportion of patients may fail to respond to initial therapy (de novo resistance). The IGF-I and EGF downstream signaling pathways are closely involved in the process of progression to therapy resistant disease. Modifications in the bioavailability of these growth factors contribute critically to disease progression. In the present review therefore, we will discuss in depth how IGF and EGF signaling participate in breast cancer pathogenesis and progression to endocrine resistant disease.
\end{abstract}

\section{Introduction}

Breast cancer is the most common type of cancer for women worldwide. Its lifetime risk amounts to a staggering total of $10 \%$ where approximately $15-20 \%$ of all breast cancers are associated with genetic predisposition [1]. It is well established that breast cancer growth is regulated by the endogenous synthesis of polypeptide growth factors [2] and by growth factors produced at distant sites [3]. Both growth factors and steroids can stimulate proliferation of steroiddependent tumor cells, and interaction between these signaling pathways occurs at several levels. Indeed, breast cancer is categorized into histopathologic subtypes based on estrogen (ER) and progesterone (PR) hormone receptor status and HER2/ErbB2 epidermal growth factor (EGF) receptors' expression levels. Namely, about $75 \%$ of all breast cancers are estrogen receptor- (ER-) positive [4]. This type of breast cancer generally has a more favorable prognosis and pattern of recurrence with endocrine therapy being the backbone of treatment. Antiestrogens and aromatase inhibitors can effectively induce tumor responses in a large proportion of these patients. However, the majority of patients progress during endocrine therapy to resistant disease (acquired resistance) and a proportion of patients may fail to respond to initial therapy (de novo resistance) [4]. Importantly, several steroid responses have now been functionally linked to other intracellular signaling pathways, including c-Src or tyrosine kinase receptors [5]. Moreover, endocrine resistant breast cancer has been correlated to the activation of other signaling pathways, including insulin-like growth factor (IGF) and epidermal growth factor (EGF) pathway [4]. Indeed, endocrine resistance is associated with overexpression of IGF and EGF 
signaling pathway components, including EGFR, HER2, IGFIR, and c-Src [6]. Dissecting signaling pathways involved in endocrine and targeted therapy resistant disease is critical for developing novel, more efficient strategies.

\section{Epidermal Growth Factors Family}

The significant role of EGF family members and their respective ErbB receptors in breast cancer cell pathogenesis is well established [7]. The EGF family consists of EGF, transforming growth factor-alpha (TGF- $\alpha$ ), heparin-binding epidermal growth factor (HB-EGF), amphiregulin (AR), epiregulin (EPR), betacellulin (BTC) and neuregulins (NRGs) $[8,9]$. All family members are synthesized as membrane-anchored precursors and their ectodomains cleaved to release the soluble form of growth factor, subsequent to a proteolytic process $[7,10]$.

The ErbB family of receptors structurally related to EGFR, is composed of ErbB1 (also known as EGFR or HER1), ErbB2 (HER2/Neu), ErbB3 (HER3), and ErbB4 (HER4) [8, 11]. Structurally, the ErbB receptors are composed of an extracellular domain rich in cysteine, a single membrane region and a large cytoplasmic domain [7]. All specific ErbB ligands have an EGF-like domain that endows them with high binding specificity $[11,12]$. The extracellular domain is the ligandbinding site of ErbB receptors whereas the cytoplasmic domain has tyrosine protein kinase activity. Mechanistically, the binding of ligands to ErbB receptors leads to their dimerization and subsequent tyrosine phosphorylation of specific tyrosine residues within the cytoplasmic tail [11]. These structural modifications enhance docking of effector proteins whose recruitment induces the activation of downstream signal transduction pathways, including Mitogen-Activated Protein Kinase (MAPK) and Phospatidylinositol-3 Kinase (PI-3K) pathways $[7,13,14]$.

\subsection{EGF Signaling in Breast Cancer Cell Proliferation. ErbB} receptors are positively correlated with breast cancer cell proliferation $[15,16]$. They are activated by the EGF ligands, EGF, a potent mitogen, being the basic ligand of these receptors, particularly in cells overexpressing EGFR $[17,18]$. In addition the ErbB receptors can autophosphorylate or be phosphorylated by other kinases [11]. The activated ErbB receptors bind to Grb2 and Sos downstream mediators, resulting in the activation of intracellular signaling pathways such as Ras/Raf, MAPK, and the PI-3K/Akt pathways which are involved in cell growth, apoptosis, invasion, and migration of breast cancer cells $[13,14,19,20]$. Specifically, the formation of EGFR-Grb7-Ras complex enhances breast cancer cell proliferation [21].

The key role of EGFR in tumor growth is evident from the antiproliferative effects of monoclonal antibodies specific for this receptor [22]. Furthermore, there is evidence that EGFR activator proteins contribute to EGFR-dependent breast cancer cell proliferation. For example, ERp57 protein, a member of the disulfide isomerase family, participates in the activation of EGFR signaling and in the modulation of its internalization leading to enhanced breast cancer cell proliferation [23]. Moreover, the stimulation of proliferation through activation of EGFR promotes degradation of Fhit protein (the product of tumor suppressor gene FHIT) [24].

A concentration-dependent effect of EGF on breast cancer cell proliferation has also been proposed [25-27]. Thus, EGF at concentrations that stimulate most other cell lines reduced the growth of MDA-468 breast cancer cells [25]. Additionally Zhang et al. [28] indicated a biphasic effect of EGF on breast cancer cell proliferation and demonstrated that Src functions as a switch of EGF signaling, depending on EGF concentration. Moreover, EGF seems to induce an inhibition of proliferation through the stimulation of an interleukin 6 type cytokine, oncostatin M, in both estrogen receptor positive and negative breast cancer cells [26]. A novel role for EGF has been proposed by Adams et al. [27]. Specifically, it was found that EGF treatments enhanced miR206 (microRNA-206) levels in MCF-7 cells, which resulted in reduced cell proliferation, enhanced apoptosis, and reduced expression of multiple estrogen-responsive genes [27].

On the other hand, ezrin-radixin-moesin-binding phosphoprotein-50 (EBP50) suppresses breast cancer cell proliferation [29]. Indeed, EBP50 can suppress EGF-induced proliferation of breast cancer cells by inhibiting EGFR phosphorylation and blocking EGFR downstream signaling [30].

\section{Insulin-Like Growth Factor Family Members}

The biological activities of IGF family not only affect the normal development of the organism but have been strongly implicated in tumorigenesis $[31,32]$. This important signaling family consists of the IGF ligands (IGF-I and IGF-II), their cell membrane receptors (IGF-IR, IGF-IIR, and IR), and a group of IGF-binding proteins (IGFBPs) [33].

Structurally, whereas insulin is composed of two domains denominated A and B, the IGFs are single-chain molecules that maintain the equivalent of the connecting $\mathrm{C}$-peptide of proinsulin between A and B domains [34]. IGFs are reported to play significant role in cancer progression and according to LeRoith et al. [33] high levels of circulating IGF-I have been indicated to constitute a risk factor for the development of breast, prostate, colon, and lung cancer. However, further clinical studies are needed to clarify these first indications.

Importantly, the expression of IGF-I is predictive of breast cancer progression, prognosis, and outcome [32]. The antiapoptotic and mitogenic actions of IGF-I are mediated by its receptor IGF-IR $[33,35]$. The IGF-IR activation and overexpression have been implicated in many cellular processes, including cell migration, proliferation, and attenuation of cell survival and are related to the malignant phenotype [31, 36, 37]. IGF-IR is a heterotetrameric transmembrane glycoprotein. Structurally, it forms a $\alpha_{2} \beta_{2}$ structure, the $\beta$ subunits endowed with intrinsic tyrosine kinase activity, whereas the $\alpha$ subunits are the ligand-binding sites [38, 39]. Binding of ligands to the receptor results in its conformational change and a subsequent autophosphorylation of tyrosine residues 1131,1135 , and 1136 in the kinase domain, juxtamembrane tyrosines, and C-terminal serines [40]. 
IGF-binding proteins and their respective concentrations regulate the bioavailability of the IGFs and IGF-induced proliferation through IGF/IGFBP complex formation [4143]. Six high-affinity IGFBPs have been identified to date. Specifically, IGFBP-1 to IGFBP-4 have similar affinities for IGF-I and IGF-II, whereas IGFBP-5 and IGFBP-6 bind IGFII with higher affinity $[44,45]$. All IGFBPs (six proteins) are expressed in mammary tumors [46, 47]. Specifically, IGFBP-4 and IGFBP-5 are expressed in primary breast cancer $[46,47]$. Thus, IGFBP- 3 provides most of the IGF-binding capacity of serum and greatly prolongs the circulating half-life of the IGFs [48]. Generally, IGFBPs modulate the interactions between IGF ligands and cell-surface receptors [48].

\subsection{IGF Signaling in Breast Cancer Cell Proliferation. IGF} family members (including IGF-I, IGF-II, and their receptors) are overexpressed in breast cancer tumor cells and were shown to promote these cells' survival and growth through various signaling pathways [32]. The principal transduction routes of the IGF signaling are MAPK and PI-3K pathways [49-51]. It is noteworthy that the MAPK and PI-3K/Akt are key mediators of cell proliferation [52-54]. Also, recent data have shown that ERK (MAPK44/42) plays an important role in the resistance of MCF-7 cells to cell apoptosis, which shows the importance of ERK signaling in the extended survival of breast cancer cells [54]. On the other hand, there is evidence that c-Jun $\mathrm{N}$-terminal kinase (JNK) signaling negatively regulates IGF-I induced breast cancer cell proliferation [55].

The majority of IGF-I cellular actions are mediated by the key signaling component of the IGF-I system, the IGF-IR [33]. The activation of IGF-IR by IGF-I results in its autophosphorylation at tyrosine residues $[33,56]$. Consecutively, the activated IGF-IR directly phosphorylates other substrates such as IRS-1, IRS-2, and IRS-4 [57]. Upon activation IRS-1 becomes a "docking" protein for other molecules, exhibiting binding sites for $\mathrm{SH} 2$ domain-containing proteins [58]. As a consequence, after IRS-1 phosphorylation, many downstream signaling pathways associated with mitogenesis, such as PI$3 \mathrm{~K}$ [59] and MAPK cascade [60,61], are activated. Other substrates which are phosphorylated by IGF-IR are srchomology $2 /$ collagen- $\alpha$ proteins (Shc) [62], growth factor receptor-binding protein 10 [63], focal adhesion kinase (FAK) [64], and carboxyl-terminal src kinase (CSK) [65].

The importance of IGF signaling in breast cancer is highlighted by reports showing that the IGF-I induced proliferation of MCF-7 breast cancer cells is attenuated with the PI3K inhibitor LY294002 and the antiestrogen ICI 182780 [66]. In addition, Ahmad et al. [49] suggested that Akt is a downstream mediator of estrogen- and IGF-I-dependent proliferation in hormone-responsive MCF-7 breast carcinoma cells. IGF-I also upregulates Cyr61, a family member of CCN family proteins with many roles in cancer progression, which is characterized by various homologous domains, including the IGF-binding protein domain, through activation of the PI-3K/Akt pathway [67]. This increase in Cyr61 leads to stimulation of breast cancer cell growth and invasion [67]. Furthermore, the inhibition of MAPK or Akt pathways prior to IGF-I stimulation prevents the expression of specific tumor suppressor miRNAs. In a novel report, [51] suggest that IGF-I signaling regulates the expression of specific miRNAs in the estrogen receptor positive MCF-7 breast cancer cell line and indicate kinase signaling as a modulator of expression for a small subset of microRNAs.

Burtrum et al. [68] show that the inhibition of IGFI signaling, via IGF-IR blockade (generation of specific monoclonal antibody), inhibits the activation of downstream MAPK and Akt signaling pathways. As a result, the proliferative potential effect of IGF-I and IGF-II was reduced. Moreover, IGF-IR deficient mice show a reduced rate of tumor growth and cell migration [69], indicating the central role of IGF-IR in breast cancer cell proliferation. Additionally, the IGF-IR suppression increases apoptosis through p38MAPK phosphorylation in MCF-7 cells [70]. Preclinical findings however have not been translated to date in effective treatment strategies [71]. The function of tumor suppressor genes influences the IGF-IR signals and their downstream proliferative effects on breast cancer cells [48]. Transcription of IGF-IR gene is negatively regulated by tumor suppressors, including the Breast Cancer Gene-1 (BRCA1), p53, and Wilms' tumor protein-1 (WT1) [72, 73]. The role of BRCA1 and BRCA2 in breast cancer progression and prognosis is well documented [74]. BRCA1 inhibits IGF-I action, so $B R C A 1$ deficiency also leads to increased expression of several IGF-I signaling pathway components in multiple experimental systems, including mice, mammary tumors, and cultured human cells $[75,76]$. As a result, mutation or deficiency of BRCA1 leads to stimulated IGF-I activity and, consequently, increased cell proliferation. Apart from this, the loss of p53 tumor suppressor gene has also been demonstrated to increase IGF-IR expression [77, 78]. This mechanism however does not involve direct DNA binding to IGF-IR promoter sequences [73]. Another example is loss of function of tumor suppressor gene PTEN which encodes a phosphatase that attenuates signals originating at tyrosine kinase receptors such as IGF-IR [32, 48].

3.2. Insulin-Like Growth Factor and Epidermal Growth Factor Signaling in Endocrine and Targeted Therapy Resistant Breast Cancer Proliferation. It is well established that both steroids and growth factors stimulate proliferation of steroiddependent tumor cells and that the interaction between these signaling pathways occurs at several levels $[6,49]$. The steroid ligands are transferred to the nucleus where they bind steroid receptors, which are classified as ligand-activated transcription factors, to activate target gene transcription and cell growth. Several steroid responses have now been functionally linked to other intracellular signaling pathways, including tyrosine kinase receptors or c-Src. Steroids such as 17 beta-estradiol (E2) via binding to cytoplasmic or membrane-associated receptors were also shown to rapidly activate intracellular signaling cascades including ERK, PI$3 \mathrm{~K}$, and STATs [79]. These E2-stimulated phosphorylationmediated cascades can then contribute to altered tumor cell function [80]. ER- $\alpha$ targeted therapy is routinely used to treat breast cancer. However, patient responses are limited by resistance to endocrine therapy $[81,82]$. The development of resistance to endocrine therapy often results in uncontrollable growth and dissemination of breast cancer 
[82]. Therefore, identifying mechanisms that drive endocrine resistance is a high clinical priority.

A large body of experimental evidence indicates that oncogenic signaling pathways underlie endocrine resistance, including EGFR, HER2, IGF-IR, c-Src, and ER itself [6]. The crosstalk between estrogen, IGF-I, and EGF signaling pathways and its involvement in endocrine resistance is well documented in breast cancer $[83,84]$. Indeed, breast cancer cells resistant to the pure steroidal ER antagonist fulvestrant demonstrate increased activation of EGFR family members and downstream ERK signaling. Moreover, EGFR has been identified as one of main genes conferring estrogen independence to human breast cancer cells [85]. E2 signaling interacts with IGF-I and EGF pathways, at different levels, for example, through the rapid activation of IGF-IR and EGFR receptors and with the consequent induction of MAPK activation in breast cancer cells [86-88]. Thus, E2 and EGF cues are obligatory in the proliferation of ductal epithelial breast cancer cells and they have synergistic effects $[5,80]$. Furthermore, the knockout of EGFR (or IGF-IR) abolished the E2-proliferative response in mice, and the inhibition of EGFR activity suppressed the proliferative effect of E2 in breast cancer cells in vitro $[79,89]$. In addition, the selective inhibitors or knockdown of both receptors diminished E2induced MAPK activation but also blocked E2-proliferative action [90]. It is proposed that E2 stimulates the expression of IGF and EGF ligands and receptors in rodent tissues and human cell lines [91]. The ER suppression in breast cancer cells prevents both EGF (and E2) stimulation of DNA synthesis [92]. However, the mitogenic effects of EGF are not mediated by ER, but it is suggested that the crosstalk between the estrogen and EGF signaling pathways may occur by other mechanisms [93]. Notably, both EGFR and c-Src stimulated pathways can induce activation of a transcription factor STAT5, which is needed for E2-induced breast cancer cell proliferation, in some cell lines [79]. Growth factor mediated ER activation is a major route through which breast cancer cells exhibit endocrine resistance to antiestrogen therapies [94]. During the genomic action of E2, binding of E2 to ER $\alpha$ results in its activation through separation from heat-shock protein 90 (Hsp90). Active ER-E2 dimer binds directly or indirectly to ERE genes (genes containing estrogen response elements) [95]. On the other hand, the nongenomic actions of E2 lead to the rapid activation of independent signaling pathways, such as IGF-IR and EGFR, depending on cell type [96]. In MCF-7 cells, estrogen potentiates the effect of IGFI on IGF-IR signaling in the promotion of cell proliferation and protection against apoptosis [97]. Specifically, ER $\alpha$ binds to the IGF-IR and activates downstream signaling pathways [98]. Moreover, Yu et al. [99] recently reported the IGF-I induced association of IGF-IR and ER $\alpha$. Furthermore, ER $\alpha$ regulates the IGF-I signaling pathways through phosphorylation of ERK1/2 and Akt where the interaction of ERIGF-IR potentiates breast cancer cell growth [99]. Selective inhibitors or knockdown of IGF-IR (and EGFR) decreased E2-induced MAPK activation and blocked E2 mitogenic effect, confirming crosstalk signaling between IGF-IR, E2, and EGFR [90]. Moreover, E2 was found to utilize a signaling pathway which involves the interactions between ER $\alpha$, IGFIR, matrix metalloproteinases, and EGF-R to activate MAPK phosphorylation [88]. A consecutive study indicated that the transcriptional activity of ligand free ER is sufficient to complement the mitogenic action of IGF-IR-induced PI3K/Akt activation [100]. On the other hand, Amin et al. [101] suggested that proliferation of MCF-7 breast cancer cells is suppressed by IGF-I-activated JNK MAPK pathway, through the induction of the SHP1 phosphatase expression.

Approximately, $15 \%$ of breast tumors are classified as triple-negative breast cancers (TNBC), a term that denotes their lack of estrogen receptor and progesterone receptor and nonamplification of the HER2 [102]. Therefore, TNBC patients cannot be treated with endocrine therapy or targeted therapies due to lack of related receptors which results in the poor prognosis. Characteristically, these patients overexpress the EGFR and IGFBP-3 proteins [103] but are resistant to tyrosine kinase inhibitors (TKIs) and anti-EGFR therapies. Up to date different mechanisms have been suggested for resistance to TKIs including EGFR independence, mutations and alterations in EGFR, and its downstream signaling pathways [104]. Efforts have focused on overcoming targeted therapy resistance. Thus, in TNBC cells a Src Family Kinases (SFKs) influenced EGFR translocation to nucleus has been reported, which in turn enhances breast cancer cell growth [105]. Within the nucleus, EGFR can function as a cotranscription factor to regulate genes involved in tumor progression [106], which has been linked to anti-EGFR therapies resistance [107]. Importantly, EGFR contributes to chemo- and radioresistance by enhancing DNA damage repair [107]. Inhibition of EGFR translocation led to a subsequent accumulation of EGFR on the plasma membrane, which greatly enhanced sensitivity of TNBC cells to antiEGFR therapy [105]. Therefore, targeting both the nuclear EGFR signaling pathway, through the inhibition of its nuclear transport, and the classical EGFR signaling pathway may prove a viable therapeutic approach. Moreover, recently it has been demonstrated that the scaffolding protein NHERF1 sensitizes EGFR-dependent tumor growth, motility, and invadopodia function to anti-EGFR (gefitinib) treatment in TNBC cells [104]. Inhibition of IGFB-3 signaling through sphingosine kinase-1 sensitizes TNBC cells to EGF receptor blockade [108]. Furthermore, the blocking of annexin A2 (a calcium-dependent phospholipid binding protein, present at the surface of triple-negative breast cancer cells) by a specific antibody suppressed the EGF-induced EGFR tyrosine phosphorylation and internalization. Treatment with this antibody also inhibited the EGFR-dependent PI3K-Akt and Raf-MEK-ERK downstream pathways, resulting in reduced cell proliferation [109]. The main IGF/EGF-related signaling mechanisms in breast cancer disease are schematically depicted in Figure 1.

\section{Bioavailability of Growth Factors}

The cellular microenvironment and modifications of extracellular matrix components (ECM) are closely correlated to malignant transformation and all the steps of the metastatic cascade [110, 111]. Namely, the tumor cells do not exist 


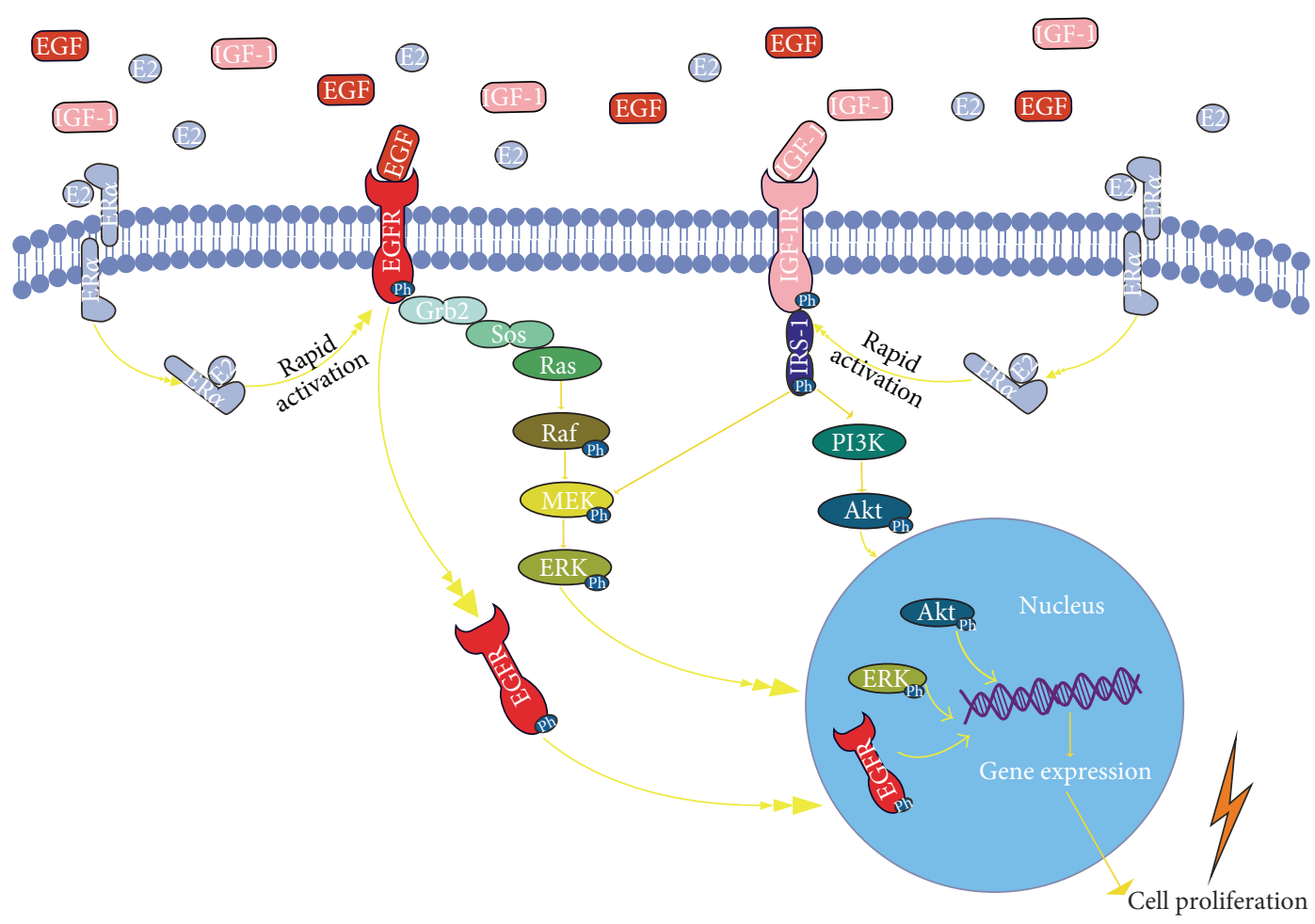

FIGURE 1: Schematic representation of IGF/EGF signaling, crosstalk with ERs. IGF-I binding to IGF-IR results in its activation and the consequent activation of PI-3K and ERK mediators. EGF-induced activation of EGFR activates the ERK and may lead to gene expression of proliferative genes via internalization of activated EGFR to nucleus. E2-ER $\alpha$ binding leads to rapid activation of EGFR and/or IGF-IR. The activation of IGF/EGF signaling pathways stimulates cell proliferation.

in isolation but rather subsist in a rich microenvironment provided by resident fibroblasts, endothelial cells, pericytes, leukocytes, and ECM components. Indeed, interactions with the tumor microenvironment or stroma are recognized as one of important "hallmarks of cancer."

In addition the ECM is characterized as a big "tank" containing various mediators including growth factors and cytokine which are either soluble or bound into structural ECM components [112]. We discuss here the fact that bioavailability of EGF and IGF-I, provided by the tumor microenvironment, modulates phenotypic plasticity, gene expression, and the recurrence rate of certain TNBC tumors. Combinatorial therapy with EGFR and IGF-IR inhibitors prevents disease progression by interrupting paracrine interactions between TNBC tumor cells and their microenvironment.

The ECM turnover and remodeling are extremely active in the tumor microenvironment [111]. The ECM components are modified through the actions of various proteases and glycosidases which results in altered ECM structure and bioavailability of key mediators [113]. Indeed, the proteolytic action of various enzymes modulates the bioavailability of soluble growth factors which via the activation of specific intracellular signaling pathways regulate critical tumor cell functions, such as migration and proliferation. The matrix metalloproteinase's family (MMP) which consists of 24 (known) zinc-dependent endopeptidases has a key role in the ECM reorganization that occurs during cancer progression
[114]. Specifically, the MMPs' action in the tumor microenvironment creates space for cancer cell migration and regulates their cell proliferation by proteolytical release and activation of the ECM-stored growth factors [114].

\section{Therapeutic Approach}

Targeting of EGF/IGF signaling pathway components has been characterized as a promising approach for breast cancer treatment. Many research groups have focused on the utilization of natural and synthetic inhibitors as well as specific antibodies for EGF family proteins as a strategy to attenuate breast cancer cell proliferation [115-117]. Gefitinib, a tyrosine kinase inhibitor, has been shown to reduce cell proliferation and tumor growth in breast cancer cell lines or in vivo conditions in xenografted animals with different levels of EGFR or HER2 expression [118]. Different combinatorial regimes have been approached; thus, the combination of gefitinib with calcitriol or their synthetic analogs resulted in a greater antiproliferative effect than with either of the agents alone in EGFR and HER2 positive breast cancer cells. These effects were due to downregulation of MAPK signaling pathway, decrease of cells in G2/M phase, and induction of apoptosis mediated by upregulation of BIM and activation of caspase 3 [119]. The utilization of monoclonal antibodies is a welldocumented approach. Thus, trastuzumab, pertuzumab, and ado-trastuzumabemtansine, which are given intravenously, are monoclonal antibodies that target the ErbB extracellular 
domains and are used for the treatment of ErbB2-positive breast cancer [120]. The effects of natural products on EGF signaling have also been investigated. Indeed, HMQ1611, a taspine derivative, with anticancer properties, has been shown to reduce the phosphorylation of EGFR and the activation of its downstream signaling mediators ERK1/2 and Akt [117]. Additionally, extracts of Livistona chinensis $\mathrm{R}$ seeds, with both anticancer and protein kinase inhibitor activity, can attenuate EGF signaling events mainly through EGFR modification [121]. Another agent, (+)-aeroplysinin1 (a natural metabolite from a type of marine sponge), abolished the proliferative effect of EGF on breast cancer cells and inhibited the ligand-induced endocytosis of the EGFR in vitro [122]. However, even though anti-EGFR or combinatorial treatments have been endorsed they are unfortunately meeting with resistance. Current research is focused on increasing our understanding on the mechanisms of response and the discovery of predictive markers. Due to overlapping and redundancy targeting several pathways simultaneously seem essential [123].

Many research groups have endeavored to inhibit the IGF-I signaling, via IGF-IR blockade $[68,124,125]$. This strategy resulted in antiproliferative effects and conclusion that IGF-IR blockade may provide a number of clinical benefits [68]. Furthermore, the effects of natural products on IGF-induced cell proliferation have also been widely studied [124-126]. Thus, it has been reported that samsum ant venom (SAV) inhibits the IGF-I mediated phosphorylation of ERK and AKT, but not p38MAPK [126]. Moreover, deguelin, a natural product isolated from several plant species, has antitumor activity, targeting IGF-IR signaling pathway via upregulation of IGFBP-3 expression [124]. Nimbolide is a terpenoid lactone derived from Azadirachta indica (Neem tree) displaying a variety of biological activities. Nimbolide decreases the proliferation of breast cancer cells by modulating the IGF signaling molecules [125]. Calycosin, a natural phytoestrogen with similar structure to estrogen, successfully induced apoptosis of MCF-7 breast cancer cells. Calycosin tends to inhibit growth by ER $\beta$-induced inhibition of IGF-IR, along with the selective regulation of MAPK and phosphatidylinositol 3-kinase (PI-3K)/Akt pathways [127]. However, even though IGF-IR appeared to be one of promising new targets and early results from clinical trials that targeted the IGF-IR and showed some evidence of response, larger randomized phase III trials have not shown clear clinical benefit of targeting this pathway in combination with conventional strategies $[71,128]$. These findings may partly be explained by the complexity of the IGF/insulin system. Thus, surface composition of the receptors, preferential expressions of IRS adaptor proteins, and expression of respective ligands may affect therapeutic outcomes and disease prognosis [129131]. Therefore, assessment of above factors may be necessary for identification of patients who would benefit from antiIGFR therapy.

\section{Conclusions}

The bridging between preclinical studies and useful clinical strategies seems to demand a deeper understanding of these complex pathways. Development of predictive molecular biomarkers and optimal inhibitory approaches of the IGF/EGF systems should yield better clinical strategies. In conclusion, unraveling the interaction between the critical signaling pathways in breast cancer biology including $\mathrm{ER} \alpha$, EGFR, and IGF components should provide additional new concepts in designing combination therapies.

\section{Conflict of Interests}

The authors declare that there is no conflict of interests regarding the publication of this paper.

\section{Acknowledgments}

Part of this research has been cofinanced by the European Union (European Social Fund (ESF)) and Greek national funds through the Operational Program "Education and Lifelong Learning" of the National Strategic Reference Framework (NSRF), Research Funding Program THALES, investing in knowledge society through the European Social Fund MIS 380222.

\section{References}

[1] M. W. Beckmann, M. R. Bani, P. A. Fasching, R. Strick, and M. P. Lux, "Risk and risk assessment for breast cancer: molecular and clinical aspects," Maturitas, vol. 57, no. 1, pp. 56-60, 2007.

[2] R. B. Dickson and M. E. Lippman, "Estrogenic regulation of growth and polypeptide growth factor secretion in human breast carcinoma," Endocrine Reviews, vol. 8, no. 1, pp. 29-43, 1987.

[3] C. L. Arteaga, L. J. Kitten, E. B. Coronado et al., "Blockade of the type I somatomedin receptor inhibits growth of human breast cancer cells in athymic mice," The Journal of Clinical Investigation, vol. 84, no. 5, pp. 1418-1423, 1989.

[4] A. Milani, E. Geuna, G. Mittica et al., "Overcoming endocrine resistance in metastatic breast cancer: current evidence and future directions," World Journal of Clinical Oncology, vol. 5, no. 5, pp. 990-1001, 2014.

[5] M. A. Shupnik, "Crosstalk between steroid receptors and the c-Src-receptor tyrosine kinase pathways: implications for cell proliferation," Oncogene, vol. 23, no. 48, pp. 7979-7989, 2004.

[6] J. M. Gee, J. F. Robertson, E. Gutteridge et al., "Epidermal growth factor receptor/HER2/insulin-like growth factor receptor signalling and oestrogen receptor activity in clinical breast cancer," Endocrine-Related Cancer, vol. 12, supplement 1, pp. S99-S111, 2005.

[7] D. J. Riese II and D. F. Stern, "Specificity within the EGF family/ErbB receptor family signaling network," BioEssays, vol. 20, no. 1, pp. 41-48, 1998.

[8] N. E. Hynes and D. F. Stern, "The biology of erbB-2/neu/HER-2 and its role in cancer," Biochimica et Biophysica Acta, vol. 1198, no. 2-3, pp. 165-184, 1994.

[9] D. Meyer and C. Birchmeier, "Multiple essential functions of neuregulin in development," Nature, vol. 378 , no. 6555, pp. 386390, 1995.

[10] J. Massagué and A. Pandiella, "Membrane-anchored growth factors," Annual Review of Biochemistry, vol. 62, pp. 515-541, 1993. 
[11] T. Holbro, G. Civenni, and N. E. Hynes, "The ErbB receptors and their role in cancer progression," Experimental Cell Research, vol. 284, no. 1, pp. 99-110, 2003.

[12] R. Pinkas-Kramarski, L. Soussan, H. Waterman et al., "Diversification of Neu differentiation factor and epidermal growth factor signaling by combinatorial receptor interactions," The EMBO Journal, vol. 15, no. 10, pp. 2452-2467, 1996.

[13] M. A. Olayioye, R. M. Neve, H. A. Lane, and N. E. Hynes, "The ErbB signaling network: receptor heterodimerization in development and cancer," The EMBO Journal, vol. 19, no. 13, pp. 3159-3167, 2000.

[14] Y. Yarden and M. X. Sliwkowski, "Untangling the ErbB signalling network," Nature Reviews Molecular Cell Biology, vol. 2, no. 2, pp. 127-137, 2001.

[15] B. Bucci, I. D’Agnano, C. Botti et al., "EGF-R expression in ductal breast cancer: proliferation and prognostic implications," Anticancer Research, vol. 17, no. 1, pp. 769-774, 1997.

[16] S. S. Skandalis, N. Afratis, G. Smirlaki et al., "Cross-talk between estradiol receptor and EGFR/IGF-IR signaling pathways in estrogen-responsive breast cancers: focus on the role and impact of proteoglycans," Matrix Biology, vol. 35, pp. 182-193, 2014.

[17] D. F. Stern, P. A. Heffernan, and R. A. Weinberg, "P185, a product of the neu proto-oncogene, is a receptorlike protein associated with tyrosine kinase activity," Molecular and Cellular Biology, vol. 6, no. 5, pp. 1729-1740, 1986.

[18] X.-F. Dong, Y. Berthois, and P. M. Martin, "Effect of epidermal growth factor on the proliferation of human epithelial cancer cell lines: correlation with the level of occupied EGF receptor," Anticancer Research, vol. 11, no. 2, pp. 737-743, 1991.

[19] E. R. Levin, "Bidirectional signaling between the estrogen receptor and the epidermal growth factor receptor," Molecular Endocrinology, vol. 17, no. 3, pp. 309-317, 2003.

[20] X. Fu, C. K. Osborne, and R. Schiff, "Biology and therapeutic potential of PI3K signaling in ER+/HER2-negative breast cancer," The Breast, vol. 22, pp. S12-S18, 2013.

[21] P.-Y. Chu, T.-K. Li, S.-T. Ding, I.-R. Lai, and T.-L. Shen, "EGFinduced Grb7 recruits and promotes ras activity essential for the tumorigenicity of Sk-Br3 breast cancer cells," The Journal of Biological Chemistry, vol. 285, no. 38, pp. 29279-29285, 2010.

[22] J. Mendelsohn and J. Baselga, "The EGF receptor family as targets for cancer therapy," Oncogene, vol. 19, no. 56, pp. 65506565, 2000.

[23] E. Gaucci, F. Altieri, C. Turano, and S. Chichiarelli, "The protein ERp57 contributes to EGF receptor signaling and internalization in MDA-MB-468 breast cancer cells," Journal of Cellular Biochemistry, vol. 114, no. 11, pp. 2461-2470, 2013.

[24] F. Bianchi, A. Magnifico, C. Olgiati et al., "FHIT-proteasome degradation caused by mitogenic stimulation of the EGF receptor family in cancer cells," Proceedings of the National Academy of Sciences of the United States of America, vol. 103, no. 50, pp. 18981-18986, 2006.

[25] J. Filmus, M. N. Pollak, R. Cailleau, and R. N. Buick, "MDA468, a human breast cancer cell line with a high number of epidermal growth factor (EGF) receptors, has an amplified EGF receptor gene and is growth inhibited by EGF," Biochemical and Biophysical Research Communications, vol. 128, no. 2, pp. 898905, 1985.

[26] S. L. Grant, A. Hammacher, A. M. Douglas et al., "An unexpected biochemical and functional interaction between gp130 and the EGF receptor family in breast cancer cells," Oncogene, vol. 21, no. 3, pp. 460-474, 2002.
[27] B. D. Adams, D. M. Cowee, and B. A. White, "The role of miR-206 in the epidermal growth factor (EGF) induced repression of estrogen receptor-alpha (EERalpha) signaling and a luminal phenotype in MCF-7 breast cancer cells," Molecular Endocrinology, vol. 23, no. 8, pp. 1215-1230, 2009.

[28] X. Zhang, J. Meng, and Z.-Y. Wang, "A switch role of Src in the biphasic EGF signaling of ER-negative breast cancer cells," PLoS ONE, vol. 7, no. 8, Article ID e41613, 2012.

[29] J.-F. Zheng, L.-C. Sun, H. Liu, Y. Huang, Y. Li, and J. He, "EBP50 exerts tumor suppressor activity by promoting cell apoptosis and retarding extracellular signal-regulated kinase activity," Amino Acids, vol. 38, no. 4, pp. 1261-1268, 2010.

[30] W. Yao, D. Feng, W. Bian et al., "EBP50 inhibits EGF-induced breast cancer cell proliferation by blocking EGFR phosphorylation," Amino Acids, vol. 43, no. 5, pp. 2027-2035, 2012.

[31] R. Baserga, A. Hongo, M. Rubini, M. Prisco, and B. Valentinis, "The IGF-I receptor in cell growth, transformation and apoptosis," Biochimica et Biophysica Acta, vol. 1332, no. 3, pp. F105F126, 1997.

[32] D. LeRoith and C. T. Roberts Jr., "The insulin-like growth factor system and cancer," Cancer Letters, vol. 195, no. 2, pp. 127-137, 2003.

[33] D. LeRoith, H. Werner, D. Beitner-Johnson, and C. T. Roberts Jr., "Molecular and cellular aspects of the insulin-like growth factor I receptor," Endocrine Reviews, vol. 16, no. 2, pp. 143-163, 1995.

[34] W. H. Daughaday and P. Rotwein, "Insulin-like growth factors I and II. Peptide, messenger ribonucleic acid and gene structures, serum, and tissue concentrations," Endocrine Reviews, vol. 10, no. 1, pp. 68-91, 1989.

[35] L. Sepp-Lorenzino, "Structure and function of the insulin-like growth factor I receptor," Breast Cancer Research and Treatment, vol. 47, no. 3, pp. 235-253, 1998.

[36] E. Surmacz, "Function of the IGF-I receptor in breast cancer," Journal of Mammary Gland Biology and Neoplasia, vol. 5, no. 1, pp. 95-105, 2000.

[37] E. A. Bohula, M. P. Playford, and V. M. Macaulay, “Targeting the type 1 insulin-like growth factor receptor as anti-cancer treatment," Anti-Cancer Drugs, vol. 14, no. 9, pp. 669-682, 2003.

[38] A. Ullrich, A. Gray, A. W. Tam et al., "Insulin-like growth factor I receptor primary structure: comparison with insulin receptor suggests structural determinants that define functional specificity," The EMBO Journal, vol. 5, no. 10, pp. 2503-2512, 1986.

[39] R. Baserga, F. Peruzzi, and K. Reiss, "The IGF-1 receptor in cancer biology," International Journal of Cancer, vol. 107, no. 6, pp. 873-877, 2003.

[40] H. Kato, T. N. Faria, B. Stannard, C. T. Roberts Jr., and D. LeRoith, "Essential role of tyrosine residues 1131, 1135, and 1136 of the insulin-like growth factor-I (IGF-I) receptor in IGF-I action," Molecular Endocrinology, vol. 8, no. 1, pp. 40-50, 1994.

[41] A. Grimberg and P. Cohen, "Role of insulin-like growth factors and their binding proteins in growth control and carcinogenesis," Journal of Cellular Physiology, vol. 183, no. 1, pp. 1-9, 2000.

[42] S. M. Firth and R. C. Baxter, "Cellular actions of the insulin-like growth factor binding proteins," Endocrine Reviews, vol. 23, no. 6, pp. 824-854, 2002.

[43] L. S. Laursen, K. Kjaer-Sorensen, M. H. Andersen, and C. Oxvig, "Regulation of insulin-like growth factor (IGF) bioactivity by sequential proteolytic cleavage of IGF binding protein- 4 and -5," Molecular Endocrinology, vol. 21, no. 5, pp. 1246-1257, 2007. 
[44] J. I. Jones and D. R. Clemmons, "Insulin-like growth factors and their binding proteins: biological actions," Endocrine Reviews, vol. 16, no. 1, pp. 3-34, 1995.

[45] C. M. Perks and J. M. P. Holly, "Insulin-like growth factor binding proteins (IGFBPs) in breast cancer," Journal of Mammary Gland Biology and Neoplasia, vol. 5, no. 1, pp. 75-84, 2000.

[46] F. Pekonen, T. Nyman, V. Ilvesmaki, and S. Partanen, "Insulinlike growth factor binding proteins in human breast cancer tissue," Cancer Research, vol. 52, no. 19, pp. 5204-5207, 1992.

[47] S. E. McGuire, S. G. Hilsenbeck, J. A. Figueroa, J. G. Jackson, and D. Yee, "Detection of insulin-like growth factor binding proteins (IGFBPs) by ligand blotting in breast cancer tissues," Cancer Letters, vol. 77, no. 1, pp. 25-32, 1994.

[48] M. N. Pollak, E. S. Schernhammer, and S. E. Hankinson, "Insulin-like growth factors and neoplasia," Nature Reviews Cancer, vol. 4, no. 7, pp. 505-518, 2004.

[49] S. Ahmad, N. Singh, and R. I. Glazer, "Role of AKT1 in 17betaestradiol- and insulin-like growth factor I (IGF-I)-dependent proliferation and prevention of apoptosis in MCF-7 breast carcinoma cells," Biochemical Pharmacology, vol. 58, no. 3, pp. 425-430, 1999.

[50] T. E. Adams, V. C. Epa, T. P. J. Garrett, and C. W. Ward, "Structure and function of the type 1 insulin-like growth factor receptor," Cellular and Molecular Life Sciences, vol. 57, no. 7, pp. 1050-1093, 2000.

[51] E. C. Martin, M. R. Bratton, Y. Zhu et al., "Insulin-like growth factor-1 signaling regulates miRNA expression in MCF-7 breast cancer cell line," PLoS ONE, vol. 7, no. 11, Article ID e49067, 2012.

[52] J. A. McCubrey, L. S. Steelman, S. L. Abrams et al., "Roles of the RAF/MEK/ERK and PI3K/PTEN/AKT pathways in malignant transformation and drug resistance," Advances in Enzyme Regulation, vol. 46, no. 1, pp. 249-279, 2006.

[53] J. Whyte, O. Bergin, A. Bianchi, S. McNally, and F. Martin, "Key signalling nodes in mammary gland development and cancer. Mitogen-activated protein kinase signalling in experimental models of breast cancer progression and in mammary gland development," Breast Cancer Research, vol. 11, no. 5, article 209, 2009.

[54] E. K. Jeong, S. Y. Lee, H. M. Jeon, M. K. Ju, C. H. Kim, and H. S. Kang, "Role of extracellular signal-regulated kinase (ERK)1/2 in multicellular resistance to docetaxel in MCF-7 cells," International Journal of Oncology, vol. 37, no. 3, pp. 655661, 2010.

[55] C. L. Mamay, A. M. Mingo-Sion, D. M. Wolf, M. D. Molina, and C. L. Van Den Berg, "An inhibitory function for JNK in the regulation of IGF-I signaling in breast cancer," Oncogene, vol. 22, no. 4, pp. 602-614, 2003.

[56] H. Kato, T. N. Faria, B. Stannard, C. T. Roberts Jr., and D. LeRoith, "Role of tyrosine kinase activity in signal transduction by the insulin-like growth factor-I (IGF-I) receptor: characterization of kinase-deficient IGF-I receptors and the action of an IGF-I-mimetic antibody ( $\alpha$ IR-3)," Journal of Biological Chemistry, vol. 268, no. 4, pp. 2655-2661, 1993.

[57] M. G. Myers Jr., X. J. Sun, and M. F. White, “The IRS-1 signaling system," Trends in Biochemical Sciences, vol. 19, no. 7, pp. 289293, 1994.

[58] M. G. Myers Jr., X. J. Sun, B. Cheatham et al., "IRS-1 is a common element in insulin and insulin-like growth factor-I signaling to the phosphatidylinositol 3'-kinase," Endocrinology, vol. 132, no. 4, pp. 1421-1430, 1993.
[59] M. G. Myers Jr., L.-M. Wang, X. J. Sun et al., "Role of IRS-1GRB-2 complexes in insulin signaling," Molecular and Cellular Biology, vol. 14, no. 6, pp. 3577-3587, 1994.

[60] E. Y. Skolnik, C. H. Lee, A. Batzer et al., "The SH2/SH3 domain-containing protein GRB2 interacts with tyrosinephosphorylated IRS1 and Shc: implications for insulin control of ras signalling," The EMBO Journal, vol. 12, no. 5, pp. 19291936, 1993.

[61] R. Baserga, C. Sell, P. Porcu, and M. Rubini, "The role of the IGF-I receptor in the growth and transformation of mammalian cells," Cell Proliferation, vol. 27, no. 2, pp. 63-71, 1994.

[62] S. Giorgetti, P. G. Pelicci, G. Pelicci, and E. Von Obberghen, "Involvement of Src-homology/collagen (SHC) proteins in signaling through the insulin receptor and the insulin-likegrowth-factor-I-receptor," European Journal of Biochemistry, vol. 223, no. 1, pp. 195-202, 1994.

[63] A. Morrione, B. Valentinis, S. Li, J. Y. T. Ooi, B. Margolis, and R. Baserga, "Grb10: a new substrate of the insulin-like growth factor I receptor," Cancer Research, vol. 56, no. 14, pp. 3165-3167, 1996.

[64] V. Baron, V. Calléja, P. Ferrari, F. Alengrin, and E. Van Obberghen, "p125(Fak) focal adhesion kinase is a substrate for the insulin and insulin-like growth factor-I tyrosine kinase receptors," The Journal of Biological Chemistry, vol. 273, no. 12, pp. 7162-7168, 1998.

[65] C. Arbet-Engels, S. Tartare-Deckert, and W. Eckhart, "Cterminal Src kinase associates with ligand-stimulated insulinlike growth factor-I receptor," The Journal of Biological Chemistry, vol. 274, no. 9, pp. 5422-5428, 1999.

[66] S. Zhang, X. Li, R. Burghardt, R. Smith III, and S. H. Safe, "Role of estrogen receptor (ER) alpha in insulin-like growth factor (IGF)-I-induced responses in MCF-7 breast cancer cells," Journal of Molecular Endocrinology, vol. 35, no. 3, pp. 433-447, 2005.

[67] S. Sarkissyan, M. Sarkissyan, Y. Wu, J. Cardenas, H. P. Koeffler, and J. V. Vadgama, "IGF-1 regulates Cyr61 induced breast cancer cell proliferation and invasion," PLoS ONE, vol. 9, no. 7, Article ID e103534, 2014.

[68] D. Burtrum, Z. Zhu, D. Lu et al., "A fully human monoclonal antibody to the insulin-like growth factor I receptor blocks ligand-dependent signaling and inhibits human tumor growth in vivo," Cancer Research, vol. 63, no. 24, pp. 8912-8921, 2003.

[69] S. Yakar, D. LeRoith, and P. Brodt, "The role of the growth hormone/insulin-like growth factor axis in tumor growth and progression: lessons from animal models," Cytokine and Growth Factor Reviews, vol. 16, no. 4-5, pp. 407-420, 2005.

[70] R. A. Mendoza, E. E. Moody, M. I. Enriquez, S. M. Mejia, and G. Thordarson, "Tumorigenicity of MCF-7 human breast cancer cells lacking the p38alpha mitogen-activated protein kinase," Journal of Endocrinology, vol. 208, no. 1, pp. 11-19, 2011.

[71] D. Yee, "Insulin-like growth factor receptor inhibitors: baby or the bathwater?" Journal of the National Cancer Institute, vol. 104, no. 13, pp. 975-981, 2012.

[72] S. Abramovitch and H. Werner, "Functional and physical interactions between BRCA1 and p53 in transcriptional regulation of the IGF-IR gene," Hormone and Metabolic Research, vol. 35, no. 11-12, pp. 758-762, 2003.

[73] R. Sarfstein, S. Maor, N. Reizner, S. Abramovitch, and H. Werner, "Transcriptional regulation of the insulin-like growth factor-I receptor gene in breast cancer," Molecular and Cellular Endocrinology, vol. 252, no. 1-2, pp. 241-246, 2006. 
[74] Q. Wang, H. Zhang, R. Fishel, and M. I. Greene, "BRCA1 and cell signaling," Oncogene, vol. 19, no. 53, pp. 6152-6158, 2000.

[75] V. Shukla, X. Coumoul, L. Cao et al., "Absence of the full-length breast cancer-associated gene-1 leads to increased expression of insulin-like growth factor signaling axis members," Cancer Research, vol. 66, no. 14, pp. 7151-7157, 2006.

[76] G. Hudelist, T. Wagner, M. Rosner et al., "Intratumoral IGFI protein expression is selectively upregulated in breast cancer patients with BRCA1/2 mutations," Endocrine-Related Cancer, vol. 14, no. 4, pp. 1053-1062, 2007.

[77] N. J. G. Webster, J. L. Resnik, D. B. Reichart, B. Strauss, M. Haas, and B. L. Seely, "Repression of the insulin receptor promoter by the tumor suppressor gene product p53: a possible mechanism for receptor overexpression in breast cancer," Cancer Research, vol. 56, no. 12, pp. 2781-2788, 1996.

[78] H. Werner and S. Maor, "The insulin-like growth factor-I receptor gene: a downstream target for oncogene and tumor suppressor action," Trends in Endocrinology and Metabolism, vol. 17, no. 6, pp. 236-242, 2006.

[79] E. M. Fox, T. M. Bernaciak, J. Wen, A. M. Weaver, M. A. Shupnik, and C. M. Silva, "Signal transducer and activator of transcription 5b, c-Src, and epidermal growth factor receptor signaling play integral roles in estrogen-stimulated proliferation of estrogen receptor-positive breast cancer cells," Molecular Endocrinology, vol. 22, no. 8, pp. 1781-1796, 2008.

[80] E. M. Fox, J. Andrade, and M. A. Shupnik, "Novel actions of estrogen to promote proliferation: integration of cytoplasmic and nuclear pathways," Steroids, vol. 74, no. 7, pp. 622-627, 2009.

[81] S. Ali, L. Buluwela, and R. C. Coombes, "Antiestrogens and their therapeutic applications in breast cancer and other diseases," Annual Review of Medicine, vol. 62, pp. 217-232, 2011.

[82] C. Barrios, J. F. Forbes, W. Jonat et al., "The sequential use of endocrine treatment for advanced breast cancer: where are we?" Annals of Oncology, vol. 23, no. 6, pp. 1378-1386, 2012.

[83] V.-I. Alexaki, I. Charalampopoulos, M. Kampa et al., "Estrogen exerts neuroprotective effects via membrane estrogen receptors and rapid Akt/NOS activation," The FASEB Journal, vol. 18, no. 13, pp. 1594-1596, 2004.

[84] B. Dufourny, J. Alblas, H. A. A. M. van Teeffelen et al., "Mitogenic signaling of insulin-like growth factor I in MCF7 human breast cancer cells requires phosphatidylinositol 3kinase and is independent of mitogen-activated protein kinase," The Journal of Biological Chemistry, vol. 272, no. 49, pp. 3116331171, 1997.

[85] T. van Agthoven, J. Veldscholte, M. Smid et al., "Functional identification of genes causing estrogen independence of human breast cancer cells," Breast Cancer Research and Treatment, vol. 114, no. 1, pp. 23-30, 2009.

[86] S. Kahlert, S. Nuedling, M. van Eickels, H. Vetter, R. Meyer, and C. Grohé, "Estrogen receptor alpha rapidly activates the IGF-1 receptor pathway," Journal of Biological Chemistry, vol. 275, no. 24, pp. 18447-18453, 2000.

[87] R. J. Pietras, "Interactions between estrogen and growth factor receptors in human breast cancers and the tumor-associated vasculature," Breast Journal, vol. 9, no. 5, pp. 361-373, 2003.

[88] R. X.-D. Song, Y. Chen, Z. Zhang et al., "Estrogen utilization of IGF-1-R and EGF-R to signal in breast cancer cells," The Journal of Steroid Biochemistry and Molecular Biology, vol. 118, no. 4-5, pp. 219-230, 2010.

[89] J. M. Hall, J. F. Couse, and K. S. Korach, "The multifaceted mechanisms of estradiol and estrogen receptor signaling," The
Journal of Biological Chemistry, vol. 276, no. 40, pp. 3686936872, 2001.

[90] R. X.-D. Song, Z. Zhang, Y. Chen, Y. Bao, and R. J. Santen, "Estrogen signaling via a linear pathway involving insulinlike growth factor I receptor, matrix metalloproteinases, and epidermal growth factor receptor to activate mitogen-activated protein kinase in MCF-7 breast cancer cells," Endocrinology, vol. 148, no. 8, pp. 4091-4101, 2007.

[91] M. H. Faulds, H. Olsen, L. A. Helguero, J.-Å. Gustafsson, and L.-A. Haldosén, "Estrogen receptor functional activity changes during differentiation of mammary epithelial cells," Molecular Endocrinology, vol. 18, no. 2, pp. 412-421, 2004.

[92] A. Migliaccio, M. Di Domenico, G. Castoria et al., "Steroid receptor regulation of epidermal growth factor signaling through Src in breast and prostate cancer cells: steroid antagonist action," Cancer Research, vol. 65, no. 22, pp. 10585-10593, 2005.

[93] B. D. Gehm, J. M. McAndrews, V. C. Jordan, and J. L. Jameson, "EGF activates highly selective estrogen-responsive reporter plasmids by an ER-independent pathway," Molecular and Cellular Endocrinology, vol. 159, no. 1-2, pp. 53-62, 2000.

[94] Y. Hawsawi, R. El-Gendy, C. Twelves, V. Speirs, and J. Beattie, "Insulin-like growth factor-oestradiol crosstalk and mammary gland tumourigenesis," Biochimica et Biophysica ActaReviews on Cancer, vol. 1836, no. 2, pp. 345-353, 2013.

[95] S. Nilsson, S. Mäkelä, E. Treuter et al., "Mechanisms of estrogen action," Physiological Reviews, vol. 81, no. 4, pp. 1535-1565, 2001.

[96] D. Yee and A. V. Lee, "Crosstalk between the insulin-like growth factors and estrogens in breast cancer," Journal of Mammary Gland Biology and Neoplasia, vol. 5, no. 1, pp. 107-115, 2000.

[97] J. Dupont and D. Le Roith, "Insulin-like growth factor 1 and oestradiol promote cell proliferation of MCF-7 breast cancer cells: new insights into their synergistic effects," Journal of Clinical Pathology: Molecular Pathology, vol. 54, no. 3, pp. 149154, 2001.

[98] R. X. Song, C. J. Barnes, Z. Zhang, Y. Bao, R. Kumar, and R. J. Santen, "The role of Shc and insulin-like growth factor 1 receptor in mediating the translocation of estrogen receptor $\alpha$ to the plasma membrane," Proceedings of the National Academy of Sciences of the United States of America, vol. 101, no. 7, pp. 20762081, 2004.

[99] Z. Yu, W. Gao, E. Jiang et al., "Interaction between IGF-IR and ER Induced by E2 and IGF-I," PLoS ONE, vol. 8, no. 5, Article ID e62642, 2013.

[100] A.-M. Gaben, M. Sabbah, G. Redeuilh, M. Bedin, and J. Mester, "Ligand-free estrogen receptor activity complements IGF1R to induce the proliferation of the MCF-7 breast cancer cells," BMC Cancer, vol. 12, article 291, 2012.

[101] S. Amin, A. Kumar, L. Nilchi, K. Wright, and M. Kozlowski, "Breast cancer cells proliferation is regulated by tyrosine phosphatase SHP1 through c-jun N-terminal kinase and cooperative induction of RFX-1 and AP-4 transcription factors," Molecular Cancer Research, vol. 9, no. 8, pp. 1112-1125, 2011.

[102] K. N. Stevens, C. M. Vachon, and F. J. Couch, "Genetic susceptibility to triple-negative breast cancer," Cancer Research, vol. 73, no. 7, pp. 2025-2030, 2013.

[103] N. M. Probst-Hensch, J. H. B. Steiner, P. Schraml et al., "IGFBP2 and IGFBP3 protein expressions in human breast cancer: association with hormonal factors and obesity," Clinical Cancer Research, vol. 16, no. 3, pp. 1025-1032, 2010.

[104] A. Bellizzi, M. R. Greco, R. Rubino et al., "The scaffolding protein NHERF1 sensitizes EGFR-dependent tumor growth, 
motility and invadopodia function to gefitinib treatment in breast cancer cells," International Journal of Oncology, vol. 46, no. 3, pp. 1214-1224, 2015.

[105] T. M. Brand, M. Iida, E. F. Dunn et al., "Nuclear epidermal growth factor receptor is a functional molecular target in triplenegative breast cancer," Molecular Cancer Therapeutics, vol. 13, no. 5, pp. 1356-1368, 2014.

[106] T. M. Brand, M. Iida, C. Li, and D. L. Wheeler, "The nuclear epidermal growth factor receptor signaling network and its role in cancer," Discovery Medicine, vol. 12, no. 66, pp. 419-432, 2011.

[107] W.-C. Huang, Y.-J. Chen, L.-Y. Li et al., "Nuclear translocation of epidermal growth factor receptor by Akt-dependent phosphorylation enhances breast cancer-resistant protein expression in gefitinib-resistant cells," The Journal of Biological Chemistry, vol. 286, no. 23, pp. 20558-20568, 2011.

[108] J. L. Martin, H. C. De Silva, M. Z. Lin, C. D. Scott, and R. C. Baxter, "Inhibition of insulin-like growth factor-binding protein-3 signaling through sphingosine kinase-1 sensitizes triple-negative breast cancer cells to egf receptor Blockade," Molecular Cancer Therapeutics, vol. 13, no. 2, pp. 316-328, 2014.

[109] P. Chaudhary, S. I. Thamake, P. Shetty, and J. K. Vishwanatha, "Inhibition of triple-negative and Herceptin-resistant breast cancer cell proliferation and migration by Annexin A2 antibodies," British Journal of Cancer, vol. 111, no. 12, pp. 2328-2341, 2014.

[110] N. Afratis, C. Gialeli, D. Nikitovic et al., "Glycosaminoglycans: key players in cancer cell biology and treatment," The FEBS Journal, vol. 279, no. 7, pp. 1177-1197, 2012.

[111] D. Nikitovic, K. Kouvidi, K. Voudouri et al., “The motile breast cancer phenotype roles of proteoglycans/glycosaminoglycans," BioMed Research International, vol. 2014, Article ID 124321, 13 pages, 2014.

[112] C. A. Kirkpatrick and S. B. Selleck, "Heparan sulfate proteoglycans at a glance," Journal of Cell Science, vol. 120, no. 11, pp. 18291832, 2007.

[113] C. Gialeli, A. D. Theocharis, and N. K. Karamanos, "Roles of matrix metalloproteinases in cancer progression and their pharmacological targeting," The FEBS Journal, vol. 278, no. 1, pp. 16-27, 2011.

[114] K. Kessenbrock, V. Plaks, and Z. Werb, "Matrix metalloproteinases: regulators of the tumor microenvironment," Cell, vol. 141, no. 1, pp. 52-67, 2010.

[115] S. Ghosh, R. K. Narla, Y. Zheng et al., "Structure-based design of potent inhibitors of EGF-receptor tyrosine kinase as anti-cancer agents," Anti-Cancer Drug Design, vol. 14, no. 5, pp. 403-410, 1999.

[116] O. M. Fattah, S. M. Cloutier, C. Kündig et al., "Peptabody-EGF: a novel apoptosis inducer targeting ErbB1 receptor overexpressing cancer cells," International Journal of Cancer, vol. 119, no. 10, pp. 2455-2463, 2006.

[117] Y. Zhan, Y. Zhang, C. Liu et al., "A novel taspine derivative, HMQ1611, inhibits breast cancer cell growth via estrogen receptor $\alpha$ and EGF receptor signaling pathways," Cancer Prevention Research, vol. 5, no. 6, pp. 864-873, 2012.

[118] J. Anido, P. Matar, J. Albanell et al., “ZD1839, a specific epidermal growth factor receptor (EGFR) tyrosine kinase inhibitor, induces the formation of inactive EGFR/HER2 and EGFR/HER3 heterodimers and prevents heregulin signaling in HER2-overexpressing breast cancer cells," Clinical Cancer Research, vol. 9, no. 4, pp. 1274-1283, 2003.

[119] M. Segovia-Mendoza, L. Díaz, M. E. González-González et al., "Calcitriol and its analogues enhance the antiproliferative activity of gefitinib in breast cancer cells," The Journal of Steroid Biochemistry and Molecular Biology, vol. 148, pp. 122-131, 2015.

[120] R. Roskoski, "The ErbB/HER family of protein-tyrosine kinases and cancer," Pharmacological Research, vol. 79, pp. 34-74, 2014.

[121] W.-C. Huang, R.-M. Hsu, L.-M. Chi, Y.-L. Leu, Y.-S. Chang, and J.-S. Yu, "Selective downregulation of EGF receptor and downstream MAPK pathway in human cancer cell lines by active components partially purified from the seeds of Livistona chinensis R. Brown," Cancer Letters, vol. 248, no. 1, pp. 137-146, 2007.

[122] M.-H. Kreuter, R. E. Leake, F. Rinaldi et al., "Inhibition of intrinsic protein tyrosine kinase activity of EGF-receptor kinase complex from human breast cancer cells by the marine sponge metabolite (+)-aeroplysinin-1," Comparative Biochemistry and Physiology-Part B: Biochemistry and, vol. 97, no. 1, pp. 151-158, 1990.

[123] A. Lluch, P. Eroles, and J.-A. Perez-Fidalgo, "Emerging EGFR antagonists for breast cancer," Expert Opinion on Emerging Drugs, vol. 19, no. 2, pp. 165-181, 2014.

[124] Y.-A. Suh, J.-H. Kim, M. A. Sung et al., "A novel antitumor activity of deguelin targeting the insulin-like growth factor (IGF) receptor pathway via up-regulation of IGF-binding protein-3 expression in breast cancer," Cancer Letters, vol. 332, no. 1, pp. 102-109, 2013.

[125] P. Elumalai, R. Arunkumar, C. S. Benson, G. Sharmila, and J. Arunakaran, "Nimbolide inhibits IGF-I-mediated PI3K/Akt and MAPK signalling in human breast cancer cell lines (MCF-7 and MDA-MB-231)," Cell Biochemistry \& Function, vol. 32, no. 5, pp. 476-484, 2014.

[126] G. Badr, O. Garraud, M. Daghestani, M. S. Al-Khalifa, and Y. Richard, "Human breast carcinoma cells are induced to apoptosis by samsum ant venom through an IGF-1-dependant pathway, PI3K/AKT and ERK signaling," Cellular Immunology, vol. 273, no. 1, pp. 10-16, 2012.

[127] J. Chen, R. Hou, X. Zhang, Y. Ye, Y. Wang, and J. Tian, “Calycosin suppresses breast cancer cell growth via ER $\beta$-dependent regulation of IGF-1R, p38 MAPK and PI3K/Akt pathways," PLoS ONE, vol. 9, no. 3, Article ID e91245, 2014.

[128] Y. Yang and D. Yee, "Targeting insulin and insulin-like growth factor signaling in breast cancer," Journal of Mammary Gland Biology and Neoplasia, vol. 17, no. 3-4, pp. 251-261, 2012.

[129] S. A. Byron, K. B. Horwitz, J. K. Richer, C. A. Lange, X. Zhang, and D. Yee, "Insulin receptor substrates mediate distinct biological responses to insulin-like growth factor receptor activation in breast cancer cells," British Journal of Cancer, vol. 95, no. 9, pp. 1220-1228, 2006.

[130] A. Gualberto, M. L. Hixon, D. D. Karp et al., "Pre-treatment levels of circulating free IGF-1 identify NSCLC patients who derive clinical benefit from figitumumab," British Journal of Cancer, vol. 104, no. 1, pp. 68-74, 2011.

[131] M. A. Becker, X. Hou, S. C. Harrington et al., "IGFBP ratio confers resistance to IGF targeting and correlates with increased invasion and poor outcome in breast tumors," Clinical Cancer Research, vol. 18, no. 6, pp. 1808-1817, 2012. 


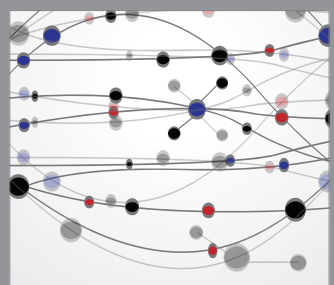

The Scientific World Journal
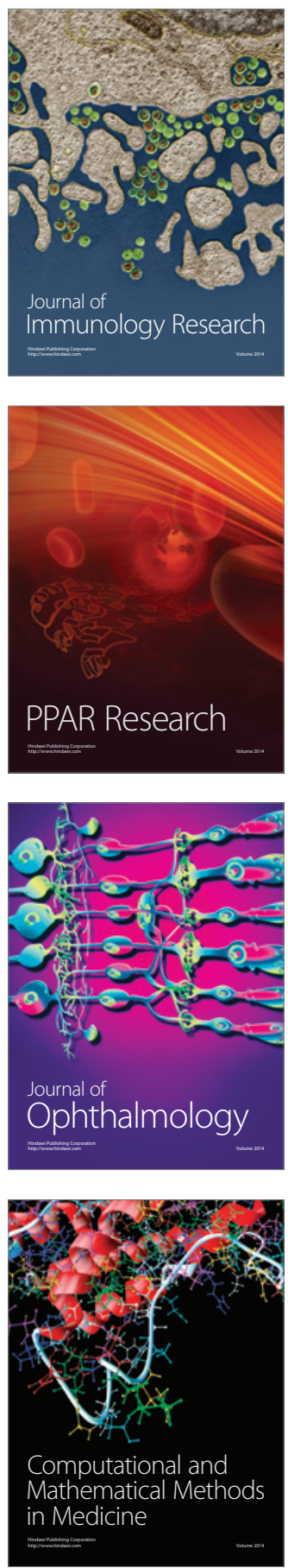

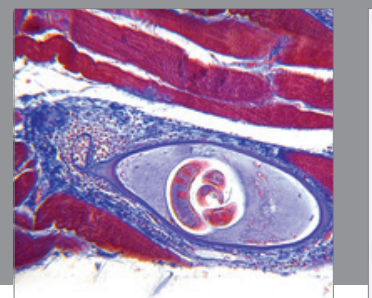

Gastroenterology

Research and Practice
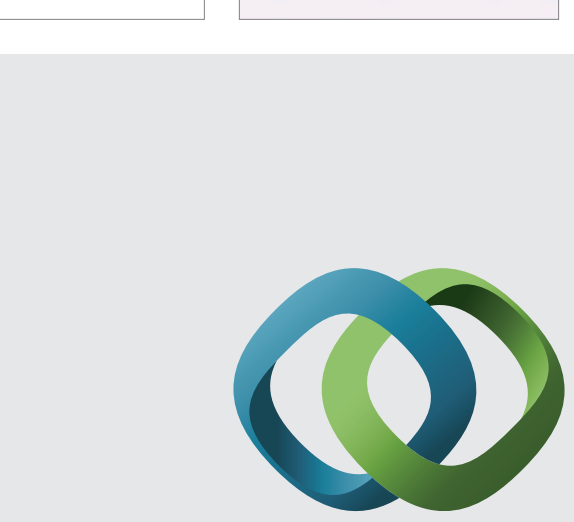

\section{Hindawi}

Submit your manuscripts at

http://www.hindawi.com
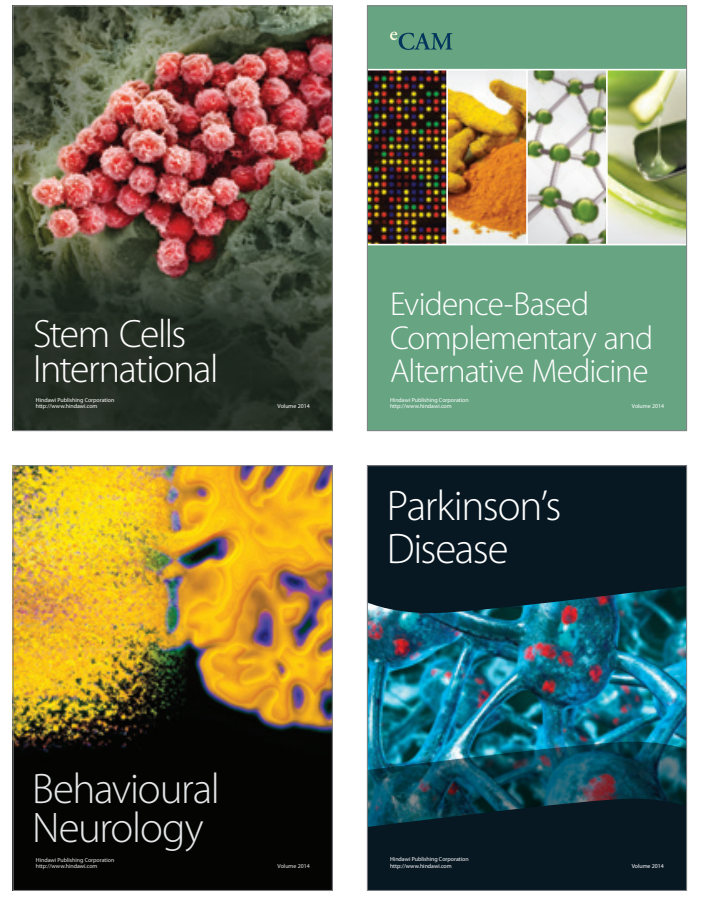
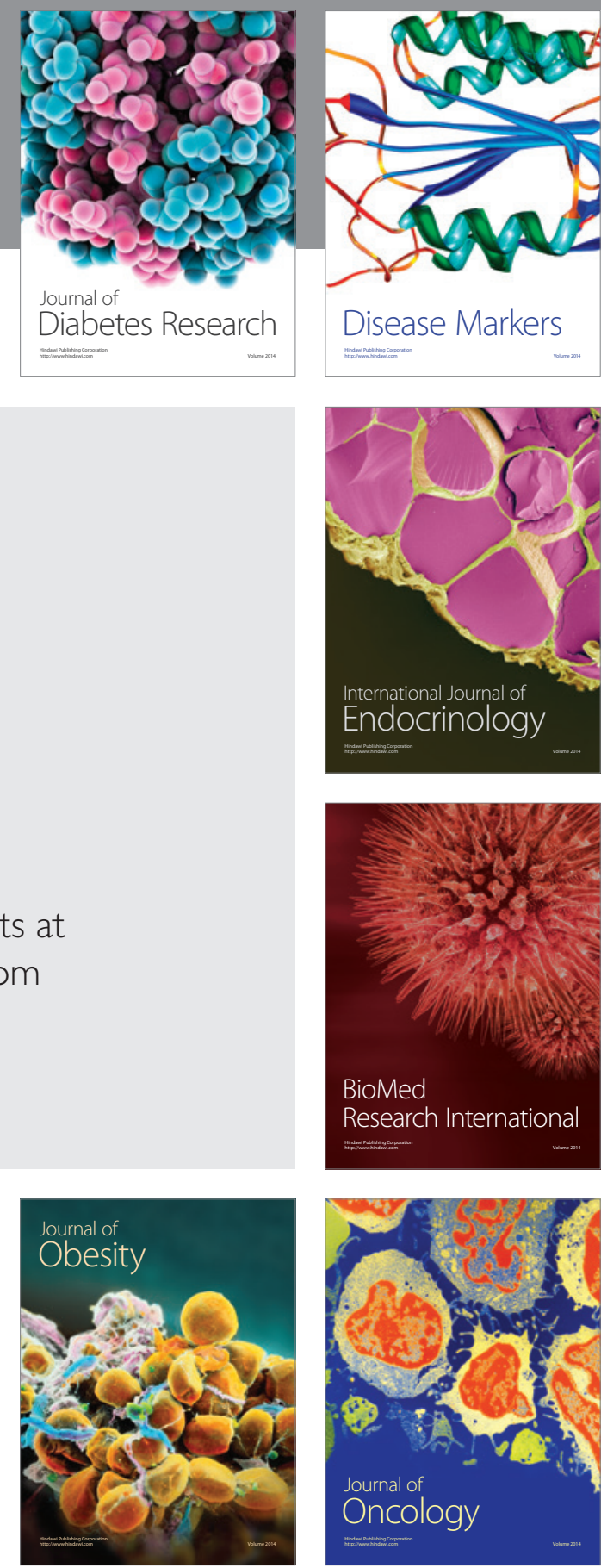

Disease Markers
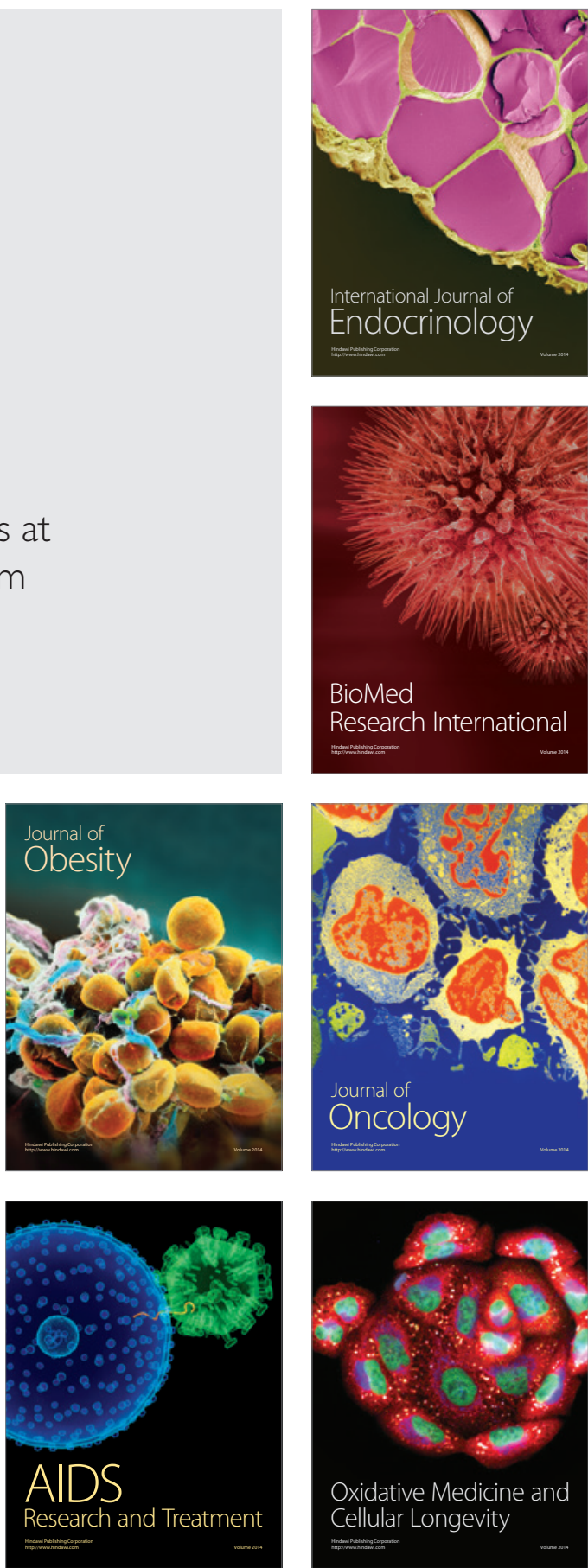